\title{
Stereocomplexes of Discrete, Isotactic Lactic Acid Oligomers Conjugated with Oligodimethylsiloxanes
}

\author{
Brigitte A. G. Lamers, ${ }^{\dagger}$ Bas van Genabeek, ${ }^{\dagger}$ J. Hennissen, $^{\dagger}$ Bas F. M. de Waal, Anja R. A. Palmans, ${ }^{\circ}$ \\ and E. W. Meijer*
}

Institute for Complex Molecular Systems and Laboratory of Macromolecular and Organic Chemistry, Eindhoven University of Technology, P.O. Box 513, 5600 MB Eindhoven, The Netherlands

Supporting Information

ABSTRACT: Discrete length block co-oligomers (BCOs) comprised of a crystalline and an amorphous block are a new class of materials that gives highly ordered lamellar morphologies at small length scales. Here, we show the preparation of discrete, isotactic oligo L- and D-lactic acid (oLLA and oDLA) homoblocks followed by ligation to oligodimethylsiloxane (oDMS), affording a library of crystalline-amorphous BCOs that vary in molecular weight and composition. Mixing the two enantiomeric BCOs or homoblocks results in the formation of the corresponding stereocomplex. The properties and phase behavior of the isotactic (block co)oligomers and the stereocomplexes thereof are studied using differential scanning calorimetry and small-angle X-ray scattering. A systematic study of the isotactic homoblock lengths and crystal structure confirmed the formation of a $10_{3}$ helix with a monomeric rise of $0.3 \mathrm{~nm}$, whereas the stereocomplex adopts a $3_{1}$ helix. The same type of crystal structure was found for the isotactic and stereocomplex of BCOs giving rise to the formation of lamellar morphologies at room temperature as a result of crystallization of the oLA blocks. Distorted lamellar structures were found in BCOs that preorganize into nonlamellar morphologies prior to crystallization. The stereocomplex BCOs shows more crystal defects and a loss of long-range ordering in the microstructure due to the larger driving force for crystallization. Hence, the balance between chain length, block volume, and the crystallization strength are of major importance for the formation of the final structure with the least defects.

\section{INTRODUCTION}

The self-organization of amorphous block copolymers (BCPs) is widely studied and has emerged as a versatile approach to obtain well-defined structures on the nano- and mesoscopic length scales. The morphologies and feature sizes of the microphase-separated structures are typically tuned by the BCP length, its composition, and the Flory-Huggins interaction parameter, $\chi^{1,2}$ In the search for minimization of feature sizes for nanoscale devices while maintaining the longrange order of the microphase-separated structures, ${ }^{3-6}$ BCP combinations with high $\chi$, low molecular weights, and narrow molar mass dispersities have been examined. ${ }^{7-11}$ Additionally, modifying the molar mass distribution can be used to tune feature sizes. ${ }^{12}$ In previous publications, we and others have shown that the molar mass dispersity $(\boxplus)$ also has a pronounced effect on the phase-segregated structure when using low molecular weight (low-MW) block co-oligomers (BCOs). ${ }^{13-16}$ In fact, BCOs with discrete molecular weights, i.e., $Ð=1.00$, form phase-segregated structures already at very low degrees of polymerization, while a high degree of longrange order is maintained. Hereby, feature sizes of down to 2.2 nm have been attained. ${ }^{17}$

The self-assembly and long-range organization into nanostructures can be enhanced by crystallization in addition to microphase segregation. In recent work, we have shown that for low-MW BCOs this leads to an increase of the long-range ordering of the BCO nanodomains. ${ }^{18,19}$ Still, a molecular understanding of the crystallization in these types of systems was not fully established. Indeed, although the self-assembly of traditional amorphous-crystalline BCPs has been studied widely, ${ }^{20,21}$ a molecular understanding of the chain packing within the microstructure is not often discussed. ${ }^{22}$ In contrast, the thermodynamics and kinetics of BCP crystallization have received much more attention, ${ }^{23}$ resulting in two general mechanisms for crystallization: confined or breakout crystallization. The first mode of crystallization results from a heterogeneous melt due to chemical incompatibility in the molten phase. Hence, the resulting morphology will depend on the BCP length and composition. ${ }^{24,25}$ In contrast, the second crystallization mode describes the self-assembly of the BCP induced by crystallization that propagates continuously throughout the homogeneous melt over a macroscopic length scale. $^{26,27}$ This results in the formation of (highly asymmetric) lamellae, irrespective of the equilibrium organization in the melt. Alternating amorphous-crystalline lamellar structures resulting from breakout crystallization are often formed in

Received: November 27, 2018

Revised: January 14, 2019

Published: January 29, 2019 
poly(L-lactic acid) (PLLA) containing BCPs. ${ }^{28,29}$ Much is known about crystallization modes and the resulting mesoscale organization, but this is not often related to molecular structure. Nevertheless, the ability to relate molecular structure to mesoscale assembly will facilitate the design of novel BCP combinations. This knowledge is crucial for the development of new materials with advanced properties and behavior. Moreover, insight into the crystallization behavior of low-MW crystalline BCOs will help close the gap between liquid crystal and BCP self-assembly. ${ }^{2,30}$

Previously, we systematically studied semicrystalline BCOs containing a discrete length oligodimethylsiloxane (oDMS) and oligomethylene (oM) block. ${ }^{19}$ By using several block lengths and topologies, a comprehensive molecular understanding was established via models that describe the chain packing within the microphase-segregated structures. Furthermore, we showed highly improved packing in a discrete BCO containing oDMS and oligo L-lactic acid (oLLA) block caused by the crystallinity of the latter. ${ }^{18}$ Here, triggered by the fascinating properties and results of discrete semicrystalline BCOs, we present an extensive study on the properties of a new set of discrete $o$ DMS-oLLA BCOs and their D-lactic acid containing enantiomers (oDMS-oDLA) (Scheme 1). We

Scheme 1. Molecular Structures of oLLA and oDLA HomoOligomers and oLLA-oDMS and oDLA-oDMS Block CoOligomers Discussed in This Work<smiles>CC(OCc1ccccc1)C(=O)O[Si](C)(C)C(C)(C)C</smiles>

\section{Bn-LLA $\mathrm{x}_{\mathrm{x}}$-TBDMS}

$x=2,4,8,12,16,24,32,64$<smiles>C[C@H](O[Si](C)(C)C(C)(C)C)C(=O)OCc1ccccc1</smiles>

\section{Bn-DLA - -TBDMS}

$\mathrm{x}=2,4,8,12,16,32,64$<smiles>CC(OCc1ccccc1)C(=O)O[C@H](C)C(C)CCC[Si](C)(C)O[Si](C)(C)C</smiles>

[LLA $-\mathbf{S i}_{\mathbf{y}}$ ]

$x=9,13,17,25,33$, $y=14,22$

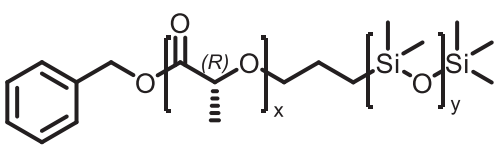

investigate the effect of crystallinity on the phase-segregated structure and increase the molecular understanding of chain packing in relation to chain length and composition. Upon mixing both enantiomers, stereocomplex formation is studied in the homoblocks and oDMS-oLA BCOs, allowing us to compare this type of crystal formation with the isotactic BCO analogues. Hereby, we expand our understanding of i-oLA homocrystallization and stereocomplex crystallization in selfassembled BCOs.

\section{RESULTS AND DISCUSSION}

L- and D-Lactic Acid Homo-Oligomer and Block CoOligomer Synthesis. Both oligo-L-lactic acid and oligo-Dlactic acid were obtained using the robust synthetic strategy for the synthesis of low-MW oLLA described by Hawker and coworkers $^{31}$ and slightly modified by us (Scheme S1). ${ }^{13}$ Via this iterative synthetic route, oLLA and oDLA with $2,4,8,12,16$, 24,32 , and 64 repeat units were obtained starting from optically pure L-lactide or D-lactide, respectively. The oligomers contained both benzyl (Bn) and tert-butyldimethylsilyl (TBDMS) end groups that we used as protective groups in the synthesis. An overview of their structures and properties is given in Table 1.

As described in our previous work, ${ }^{18}$ ligation of hydroxylterminated oLLA with a discrete siloxane block involved the preparation of an L-lactic acid end-capped oligodimethylsiloxane (Scheme S2). Still, the newly attained oDLA required the preparation of discrete oDMS derivatized with D-lactic acid, obtained via the commercially available methyl ester of D-lactic acid (Scheme S3). This resulted in two series of BCOs: one incorporating L-lactic acid residues, which we abbreviate as $\left[\mathrm{LLA}_{x}-\mathrm{Si}_{y}\right]$, and the other containing the enantiomeric D-lactic acid $\left(\left[\mathrm{DLA}_{x}-\mathrm{Si}_{y}\right]\right)$ (Table 2, Figure 1). Here $x$ and $y$ are the number of lactic acid and siloxane repeat units, respectively.

Thermal and Crystalline Properties of oLLA and oDLA. Most of L- and D-lactic acid-derived oligomers were obtained as white, crystalline solids at room temperature. Only the shortest oligomers (up to 8 lactic acid units) did not directly crystallize upon cooling from a molten sample but initially remained a viscous oil. The effect of the end groups on the material properties turned out to be negligible (Figure S1), and therefore, we will focus on the thermal properties of the oligomers that have both the $\mathrm{Bn}$ and the TBDMS end groups attached. The data obtained from differential scanning calorimetry (DSC) is summarized in Table 1.

In general, the DSC profiles can be divided into 3 categories: A, B and C, of which categories $\mathrm{B}$ and $\mathrm{C}$ have been studied before by Hawker and co-workers. ${ }^{31}$ Category A represents all materials that do not directly crystallize upon cooling from the isotropic melt but enter a glassy state. Furthermore, upon heating, only a glass transition is observed. All lactic acid oligomers with $2,4,8$, or 12 repeat units show this behavior. After prolonged storage at room temperature (up to 12 months), most of these materials crystallized. DSC analyses of the crystallized samples showed the absence of a glass transition and the appearance of a melting transition. After melting of the samples during the first heating ramp, only glass transitions could be observed in successive cycles (Figure S2A). Oligomers Bn-LLA - TBDMS, Bn-DLA 2 -TBDMS, and Bn-LLA - TBDMS did not crystallize within a 24 month time frame. It is not fully understood why the latter did not crystallize, whereas the enantiomeric Bn-DLA - TBDMS did. Probably the rate of nucleation is extremely low and very sensitive to remaining traces of solvent or heterogeneous impurities. Oligomers in category B (16 and 24 lactic acid repeat units) also did not crystallize upon cooling from the isotropic melt. However, during heating, a glass transition was followed by an exothermic cold-crystallization transition and finally a sharp melting transition (Figure S2B). Category C holds the remaining, highest MW oligomers with 32 or 64 lactic acid repeat units. These materials directly crystallized when cooling from the isotropic melt with $10 \mathrm{~K} \mathrm{~min}^{-1}$ yet at temperatures that were significantly lower than the values for $T_{\mathrm{m}}\left(\Delta T>30^{\circ} \mathrm{C}\right)$. Additionally, oligomers Bn-LLA ${ }_{64}$-TBDMS and $\mathrm{Bn}-\mathrm{DLA}_{64}$-TBDMS revealed a combination of a melting transition at $T_{\mathrm{m}, 1}$ followed by an exothermic crystallization, and subsequently a second melting transition at $T_{\mathrm{m}, 2}$ (Figure S2C). 


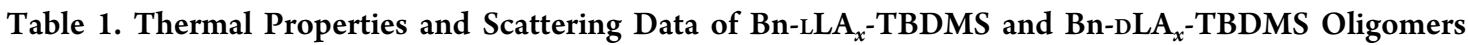

\begin{tabular}{|c|c|c|c|c|c|c|c|}
\hline entry & oligomer $^{a}$ & $M_{\mathrm{n}}^{b}[\mathrm{Da}]$ & $\mathrm{T}_{\mathrm{g}}{ }^{c}\left[{ }^{\circ} \mathrm{C}\right]$ & $T_{\mathrm{m}}{ }^{c}\left[{ }^{\circ} \mathrm{C}\right]$ & $\Delta H_{\text {fus }}{ }^{c}\left[\mathrm{~kJ} \mathrm{~mol}^{-1}\right]$ & Cat. $^{d}$ & $d_{\mathrm{LAM}}{ }^{e}[\mathrm{~nm}]$ \\
\hline 1 & $\mathrm{oLLA}_{2}$ & 367 & n.d. & n.o. & n.o. & A & n.o. \\
\hline 2 & $o \mathrm{DLA}_{2}$ & & -66.7 & n.o. & n.o. & A & n.o. \\
\hline 3 & $o \mathrm{LLA}_{4}$ & 511 & -32.0 & 42.0 & 33.1 & A & n.o. \\
\hline 4 & $o \mathrm{DLA}_{4}$ & & -32.5 & 39.0 & 35.2 & A & n.o. \\
\hline 5 & $o \mathrm{LLA}_{8}$ & 799 & -3.8 & n.o. & n.o. & A & n.o. \\
\hline 6 & $o \mathrm{DLA}_{8}$ & & -1.2 & 39.3 & 44.9 & A & 3.4 \\
\hline 7 & $o \mathrm{LLA}_{12}$ & 1087 & 10.9 & 64.4 & 39.1 & A & 4.7 \\
\hline 8 & $o \mathrm{DLA}_{12}$ & & 12.8 & 65.8 & 73.4 & A & 4.7 \\
\hline 9 & $o \mathrm{LLA}_{16}$ & 1374 & 23.2 & 89.6 & 70.9 & B & 6.0 \\
\hline 10 & $o \mathrm{DLA}_{16}$ & & 23.1 & 89.4 & 73.5 & B & 5.9 \\
\hline 11 & $o \mathrm{LLA}_{24}$ & 1952 & 29.7 & 120.9 & 101.1 & B & 8.2 \\
\hline 12 & $o \mathrm{LLA}_{32}$ & 2528 & n.d. & 139.9 & 195.9 & $\mathrm{C}$ & 10.7 \\
\hline 13 & $o \mathrm{DLA}_{32}$ & & 37.7 & 135.4 & 189.8 & $\mathrm{C}$ & 10.7 \\
\hline \multirow[t]{2}{*}{14} & $o \mathrm{LLA}_{64}$ & 4834 & n.d. & $135.1^{f}$ & 291.9 & $\mathrm{C}$ & 10.1 and $15.8^{g}$ \\
\hline & & & & 152.0 & & & \\
\hline \multirow[t]{2}{*}{15} & $o \mathrm{DLA}_{64}$ & & 42.1 & $141.0^{f}$ & 377.5 & $\mathrm{C}$ & 10.6 \\
\hline & & & & 164.9 & & & \\
\hline
\end{tabular}

${ }^{a}$ Lactic acid oligomers contain benzyl and TBDMS end groups. The subscript number represents the number of lactic acid repeat units. ${ }^{b}$ Calculated value of $M_{\mathrm{n}} \cdot{ }^{c}$ Glass transition temperature $\left(T_{\mathrm{g}}\right)$, melt temperature $\left(T_{\mathrm{m}}\right)$, and enthalpy of fusion $\left(\Delta H_{\text {fus }}\right)$. Determined with DSC using a heating rate of $10 \mathrm{~K} \mathrm{~min}^{-1}$. Enthalpic values are per mole of oligomer. ${ }^{d}$ Thermal behavior category, see main text. ${ }^{e}$ Lamellar domain spacing determined with SAXS at room temperature, calculated as $d_{\mathrm{LAM}}=2 \pi / q^{*} .{ }^{f}$ Two melting transitions are observed: $T_{\mathrm{m}, 1}($ first $)$ and $T_{\mathrm{m}, 2}\left(\right.$ second). ${ }^{g} \mathrm{~A}$ mixture of two lamellar structures was observed; n.d. = not determined; n.o. = not observed.

Table 2. Thermal and Morphological Characterization of $\left[\mathrm{LLA}_{x}-\mathrm{Si}_{y}\right]$ and $\left[\mathrm{DLA}_{x}-\mathrm{Si}_{y}\right] \mathrm{BCOs}$

\begin{tabular}{|c|c|c|c|c|c|c|c|c|c|}
\hline entry & $\mathrm{BCO}^{a}$ & $M_{\mathrm{n}}^{b}[\mathrm{Da}]$ & $f_{\mathrm{LA}}{ }^{c}$ & $T_{\mathrm{g}}{ }^{d}\left[{ }^{\circ} \mathrm{C}\right]$ & $T_{\mathrm{m}}{ }^{d}\left[{ }^{\circ} \mathrm{C}\right]$ & $\Delta H_{\mathrm{fus}}{ }^{d}\left[\mathrm{~kJ} \mathrm{~mol}{ }^{-1}\right]$ & $\mathrm{T}_{\mathrm{ODT}}{ }^{d}\left[{ }^{\circ} \mathrm{C}\right]$ & $d_{\text {cryst }}^{e}[\mathrm{~nm}]$ & $d_{\text {amorph }}^{f}[\mathrm{~nm}]$ \\
\hline 1 & {$\left[\mathrm{LLA}_{17}-\mathrm{Si}_{15}\right]$} & 2486 & 0.47 & n.o. & 85.1 & 78.3 & $79.1^{g}$ & 11.7 & n.o. \\
\hline 2 & {$\left[\mathrm{DLA}_{17}-\mathrm{Si}_{15}\right]$} & 2486 & 0.47 & n.o. & 81.5 & 76.1 & n.o. & 12.1 & n.o. \\
\hline 3 & {$\left[\mathrm{LLA}_{9}-\mathrm{Si}_{23}\right]$} & 2502 & 0.25 & -24.8 & n.o. & n.o. & 31.2 & n.o. & $6.3\left(\mathrm{CYL}, 25{ }^{\circ} \mathrm{C}\right)$ \\
\hline 4 & {$\left[\mathrm{DLA}_{9}-\mathrm{Si}_{23}\right]$} & 2502 & 0.25 & -31.4 & n.o. & n.o. & 26.9 & n.o. & $6.4\left(\mathrm{CYL}, 25^{\circ} \mathrm{C}\right)$ \\
\hline 5 & {$\left[\mathrm{LLA}_{13}-\mathrm{Si}_{23}\right]$} & 2791 & 0.31 & n.d. & 42.5 & 38.2 & 75.7 & 11.3 & $7.1\left(\mathrm{CYL}, 55^{\circ} \mathrm{C}\right)$ \\
\hline 6 & {$\left[\mathrm{DLA}_{13}-\mathrm{Si}_{23}\right]$} & 2791 & 0.31 & n.d. & 39.5 & 34.3 & 73.4 & 11.6 & n.d. \\
\hline 7 & {$\left[\mathrm{LLA}_{17}-\mathrm{Si}_{23}\right]$} & 3079 & 0.36 & n.d. & 80.8 & 63.7 & 97.5 & 12.8 & $7.7\left(\mathrm{GYR}, 91^{\circ} \mathrm{C}\right)$ \\
\hline 8 & {$\left[\mathrm{DLA}_{17}-\mathrm{Si}_{23}\right]$} & 3079 & 0.36 & n.d. & 78.9 & 66.5 & 94.2 & 12.8 & n.d. \\
\hline 9 & {$\left[\mathrm{LLA}_{25}-\mathrm{Si}_{23}\right]$} & 3655 & 0.45 & n.d. & 117.2 & 130.8 & 157.3 & 12.8 & $8.3\left(\mathrm{LAM}, 145^{\circ} \mathrm{C}\right)$ \\
\hline 10 & {$\left[\mathrm{LLA}_{33}-\mathrm{Si}_{23}\right]$} & 4232 & 0.52 & n.d. & 139.2 & 205.5 & 187.7 & 15.2 & $9.1\left(\mathrm{LAM}, 145^{\circ} \mathrm{C}\right)$ \\
\hline
\end{tabular}

${ }^{a}$ Block co-oligomers $\left[\mathrm{LLA}_{x}-\mathrm{Si}_{y}\right]$ and $\left[\mathrm{DLA}_{x}-\mathrm{Si}_{y}\right]$ as depicted in Scheme $1 .{ }^{b}$ Calculated value of $M_{\mathrm{n}} \cdot{ }^{c}$ Volume fraction of the crystalline block, calculated using bulk densities for PDMS $\left(0.95 \mathrm{~g} \mathrm{~mL}^{-1}\right)^{13,14}$ and PLLA $\left(1.29 \mathrm{~g} \mathrm{~mL}^{-1}\right) .{ }^{34}{ }^{d}$ Glass transition temperature $\left(T_{\mathrm{g}}\right)$, melt temperature $\left(T_{\mathrm{m}}\right)$, amorphous order-disorder transition $\left(T_{\mathrm{ODT}}\right)$, and enthalpy of fusion $\left(\Delta H_{\text {fus }}\right)$. Determined with DSC using a heating rate of $10 \mathrm{~K} \mathrm{~min}{ }^{-1}$. Enthalpic values are per mole of oligomer. ${ }^{e}$ Lamellar domain spacing of the crystalline phase determined with SAXS at room temperature, calculated as $d_{\mathrm{LAM}}=2 \pi / q^{*} .{ }^{f}$ Domain spacing of the amorphous phase separated state above $T_{\mathrm{m}}$ (exact temperature noted in brackets). CYL $=$ cylindrical, GYR = gyroid, LAM = lamellar phase. ${ }^{g}$ Transition was only observed in the cooling run; n.d. $=$ not determined; n.o. $=$ not observed.

Moreover, Bn-DLA 32 -TBDMS and Bn-DLA 64 -TBDMS can be forced into a glassy state by rapid cooling $\left(\right.$ rate $=40 \mathrm{~K} \mathrm{~min}^{-1}$ ) from the isotropic melt (Figure S2D). Because of the high cooling rate, nucleation was retarded and a glass transition was observed instead. During heating, cold crystallization occurred, followed by melting transitions, as described above.

The packing of the crystalline lactic acid oligomers in bulk at room temperature was investigated with small-angle X-ray scattering (SAXS). Two-dimensional (2-D) transmission scattering data were acquired in medium- and wide-angle modes (MAXS and WAXS; $0.1<q<30 \mathrm{~nm}^{-1}$ ), resulting in one-dimensional (1-D) scattering profiles that captured all potential organization over a size range of $0.2-60 \mathrm{~nm}$. A selection of scattering profiles is shown in Figure 2. All solidified lactic acid oligomers with 8 or more repeat units exhibit a well-structured, lamellar macrolattice, as indicated by the sharp, equally spaced scattering peaks in the MAXS region (labeled with $\left.q^{*}, \sqrt{4} q^{*}, \sqrt{ } 9 q^{*}, \ldots\right)$. Interestingly, Bn-LLA $64^{-}$
TBDMS seems to consist of two lamellar structures with a different lamellar thickness, of which we labeled the two sets of principal and related higher order reflections with $q^{*}$ and $q_{2}{ }^{*}$, respectively.

The lamellar spacings $\left(d_{\text {LAM }}\right)$ are listed in Table 1 and plotted as a function of the number of repeat units in Figure 3. Separate linear fits through the data points for both enantiomeric sets (excluding the points for the oligomers with 64 repeat units) reveal near-perfect linear correlations between the number of repeat units and the lamellar thickness. An increase of $0.306 \pm 0.003$ and $0.298 \pm 0.003 \mathrm{~nm}$ per monomeric residue was found for $o$ LLA and oDLA, respectively. These values are very close to the reported value of $0.278 \mathrm{~nm}$ for one monomeric LLA unit. $^{32}$

Furthermore, additional scattering reflections owing to the oligolactic acid crystal lattice were present in the $q=5-20$ $\mathrm{nm}^{-1}$ WAXS domain (Figure $2 \mathrm{~B}$ ). Obviously, noncrystallized oligomers Bn-LLA 2 -TBDMS, Bn-DLA 2 -TBDMS, and Bn-LLA ${ }_{8}^{-}$ 


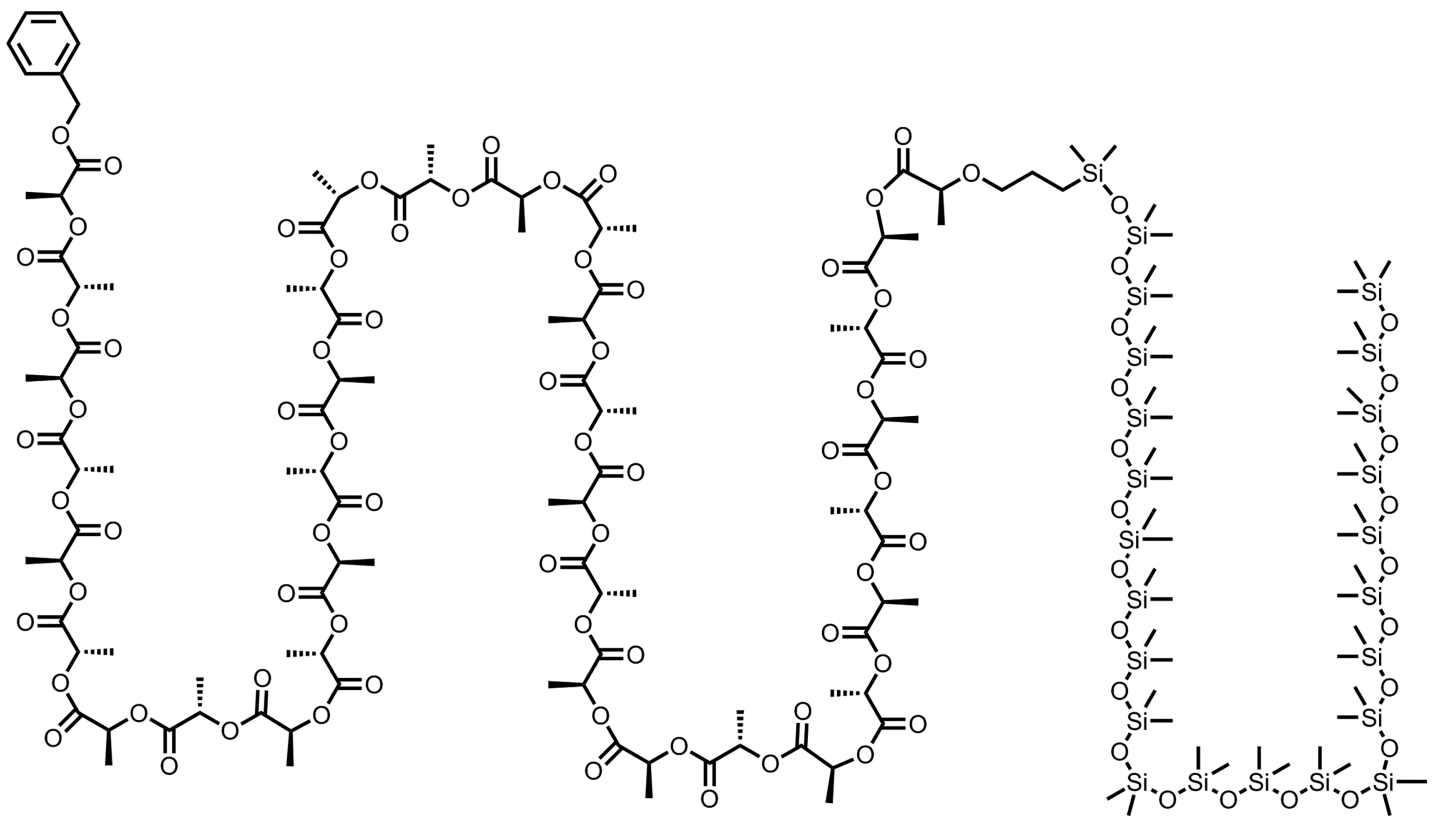

Figure 1. Chemical structure of longest $\mathrm{BCO}$ discussed in this work: $o \mathrm{LLA}_{33}-o \mathrm{DMS}_{23}$.
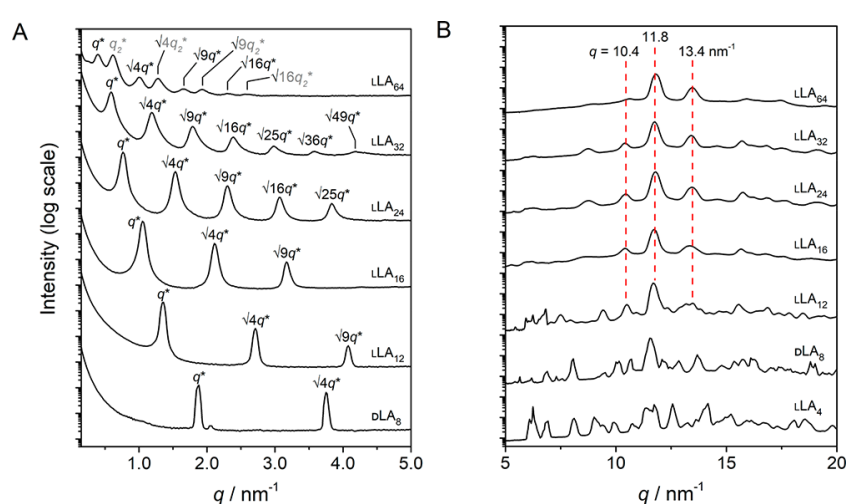

Figure 2. 1-D transmission scattering profiles for lactic acid oligomers (with protective groups present) of various lengths in the low- $q$ range (A) and high- $q$ range (B).

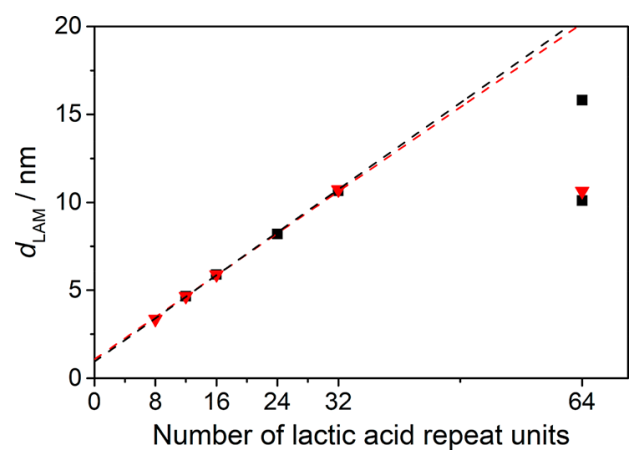

Figure 3. Lamellar domain spacing $d^{*}$ of oLLA (black squares) and $o$ DLA (red upside down triangles) as a function of the number of repeat units. Dashed lines are individual linear fits for both enantiomeric sets (black for oLLA, red for oDLA) through all data points except those for the oligomers with 64 repeat units.

TBDMS showed no scattering reflections in this region. Although a large number of sharp yet not fully resolved reflections were present for the shortest crystalline oligomer Bn-LLA - TBDMS - for which no reflections at lower $q$ values were found-only broad, overlapping reflections remained for the longer oligomers. For oligomers with 16 repeat units or more, the positions of the three most pronounced reflections at 10.4 ([011]), 11.8 ([110], [200]), and $13.4([203]) \mathrm{nm}^{-1}$ are indicated with the red, dashed lines. Those reflections perfectly match the ones found for crystalline PLLA. ${ }^{33}$ Consequently, we may assume that these oligomers crystallize in pseudoorthorhombic unit cells containing two oligolactic acid molecules oriented in $10_{3}$ helices parallel to the unit cell $c$ axis (cell dimensions: $a=1.07 \mathrm{~nm}, b=0.595 \mathrm{~nm}$, and $c=2.78$ $\mathrm{nm}$ ). As such, the lamellar domains described above most probably consist of unfolded oLLA or oDLA molecules-in a $10_{3}$ helix-oriented perpendicular to the lamellar planes. Indeed, the increase of the lamellar thickness with approximately $0.3 \mathrm{~nm}$ per additional monomeric residue very closely resembles the length of the unit cell $c$ axis divided by 10 . Oligomers $\mathrm{LLA}_{64}$ and $\mathrm{DLA}_{64}$ form an exception: both show lower values for $d_{\text {LAM }}$ than expected. For these lengths the gain of entropy that results from chain folding most likely overcomes the enthalpic penalty that is associated with this packing mode.

Thermal Properties of oDMS-oLLA and oDMS-oDLA Block Co-oligomers. In contrast to the atactic BCOs earlier studied, which were obtained as soft, waxy substances at room temperature, ${ }^{13}$ we found that the BCOs containing an isotactic $o$ LLA or $o$ DLA block appeared as crystalline, white solids. Only $\left[\mathrm{LLA}_{9}-\mathrm{Si}_{23}\right]$ and $\left[\mathrm{DLA}_{9}-\mathrm{Si}_{23}\right]$ remained liquid-like at room temperature. We first examine the thermal properties of the BCOs using DSC, similar to our previous work on the symmetric $\mathrm{BCO}\left[\mathrm{LLA}_{17}-\mathrm{Si}_{15}\right]{ }^{18}$ Figure $4 \mathrm{~A}$ displays DSC thermograms (heating traces) for a selection of L-LA BCOs. As expected, the thermograms of $\left[\mathrm{DLA}_{x}-\mathrm{Si}_{y}\right]$ are very similar to their BCO enantiomers (Figure S3). Typically, two reversible transitions can be observed during heating: a major endothermic transition ( $\gg 10 \mathrm{~kJ} \mathrm{~mol}^{-1}$ ) and a second, much weaker endotherm $\left(\sim 2 \mathrm{~kJ} \mathrm{~mol}^{-1}\right)$ at higher temperatures. An exothermic transition was observed upon cooling the sample with $10 \mathrm{~K} \mathrm{~min}^{-1}$ (Figures $4 \mathrm{~B}$ and S4). The two most 

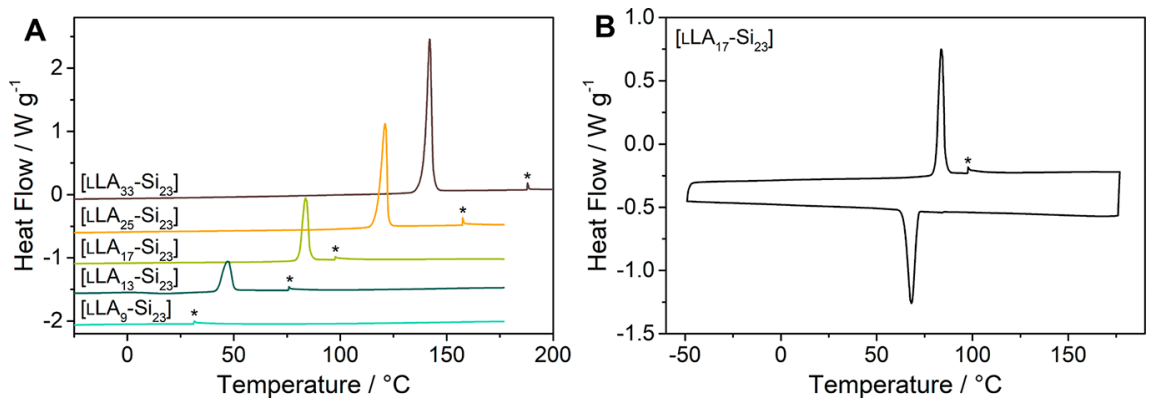

Figure 4. DCS traces (second heating run) for $\left[\mathrm{LLA}_{x}-\mathrm{Si}_{23}\right] \mathrm{BCOs}(\mathrm{A})$ and complete DSC trace including second heating and cooling run of $\left[\mathrm{LLA}_{17^{-}}\right.$ $\left.\mathrm{Si}_{23}\right]$ (B). Order-disorder transition unrelated to the crystallization process is indicated with an asterisk. Endothermic heat flows have a positive value. Temperature ramp of $10 \mathrm{~K} \mathrm{~min}^{-1}$ was used.

asymmetric $\mathrm{BCOs}\left[\mathrm{LLA}_{9}-\mathrm{Si}_{23}\right]$ and $\left[\mathrm{DLA}_{9}-\mathrm{Si}_{23}\right]\left(f_{\mathrm{LA}}=0.25\right)$ only exhibited a single, weak $\left(\sim 2 \mathrm{~kJ} \mathrm{~mol}^{-1}\right)$ transition.

As already discussed for BCO $\left[\mathrm{LLA}_{17}-\mathrm{Si}_{15}\right]$ in earlier work, ${ }^{18}$ we attribute the most prominent transitions to a melting (and related crystallization) event of the oligolactic acid block. Before describing the weak transition indicative for an orderdisorder transition at temperatures above the melting temperature (vide infra), we first discuss the crystallization of the BCOs. Interestingly, nearly all BCOs with an oligolactic acid block with more than 9 monomeric residues directly crystallized upon cooling. In contrast to a number of the individual oLLA and oDLA molecules, no glass transitions or cold-crystallization effects could be observed. This indicates a more facile formation of crystalline oligolactic acid nuclei if ligated with an $o$ DMS block and thus upon crystallization from the phase-segregated state. A single exception was $\mathrm{BCO}$ $\left[\mathrm{DLA}_{13}-\mathrm{Si}_{23}\right]$, for which a $T_{\mathrm{g}}$ and $T_{\mathrm{CC}}$ could be determined (Figure S3A). The origin of this anomaly-enantiomer $\left[\mathrm{LLA}_{13}{ }^{-}\right.$ $\mathrm{Si}_{23}$ ] did crystallize directly upon cooling-is not known, yet suggests that the crystallization kinetics of the shortest crystalline oligolactic acid blocks presumably remains very sensitive toward external factors (e.g., traces of solvent). When comparing the melting points of the BCOs with those of pristine $o$ LLA and $o \mathrm{DLA}$, we noticed that the melting points of the BCOs (following the red dashed line in Figure 5) typically are lower than those of the oligolactic acid building blocks. Most likely this difference is the result of destabilization of the $o$ LA crystal phase in the BCO due to the high interfacial energy between oLA and oDMS domains. This is most pronounced for the shortest analogues. Extrapolation of the red dashed line for even shorter oligolactic acid block lengths

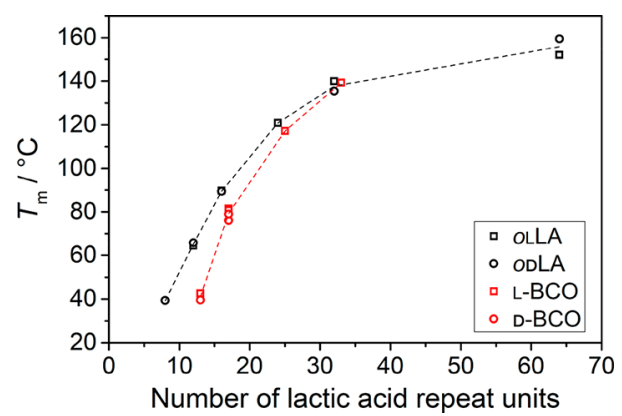

Figure 5. Melting points of oLLA (black open squares), oDLA (black open circles), $\left[\mathrm{LLA}_{x}-\mathrm{Si}_{y}\right]$ (red open squares), and $\left[\mathrm{DLA}_{x}-\mathrm{Si}_{y}\right]$ (red open circles) as a function of the number of lactic acid repeat units $x$. Dashed black and red lines are added to guide the eye. shows that the location of the melting point rapidly approaches that of the glass transition. This corroborates the absence of a crystalline phase in $\mathrm{BCOs}\left[\mathrm{LLA}_{9}-\mathrm{Si}_{23}\right]$ and $\left[\mathrm{DLA}_{9}-\mathrm{Si}_{23}\right]$ even after storage of these compounds for multiple weeks at 4 or $-20{ }^{\circ} \mathrm{C}$.

The weak thermal transition (indicated with an asterix in Figure 4) is ascribed to the order-disorder transition given the low enthalpic footprint and comparability of the orderdisorder transition temperatures $\left(T_{\mathrm{ODT}}\right)$ with those of fully amorphous oLA-oDMS BCOs that include an atactic oligolactic acid block. ${ }^{13}$ Still, the $T_{\text {ODT }}$ values of the BCOs that contain an isotactic lactic acid block are systematically higher $\left(6-20{ }^{\circ} \mathrm{C}\right.$ difference) than those of amorphous $o \mathrm{LA}$ $o \mathrm{DMS} \mathrm{BCOs}$ of equal length and composition. This suggests that the effective interaction parameter, $\chi_{\text {eff }}$, between $o$ DMS and $o$ LLA or $o$ DLA blocks is larger than that of the combination $o$ DMS and atactic oLA. ${ }^{35}$

Microphase Separation in oLLA-oDMS and oDLAoDMS Block Co-Oligomers. The presence of ordered microphase-separated structures below $T_{\mathrm{m}}$ (or $T_{\mathrm{ODT}}$ ) was examined with SAXS at room temperature. The 1-D scattering profiles resulting from the radial averaging of the scattering data is depicted in Figure 6A for $\left[\mathrm{LLA}_{x}-\mathrm{Si}_{y}\right]$ and Figure S5 for $\left[\mathrm{DLA}_{x}-\mathrm{Si}_{y}\right]$. All BCOs showed a primary reflection peak at $q^{*}<$ $1 \mathrm{~nm}^{-1}$ and two or more higher order reflections, confirming the presence of an ordered (microphase separated) structure in all BCOs at room temperature. Related domain sizes were calculated as $d=2 \pi / q^{*}$ and are tabulated as $d_{\text {cryst }}$ for the BCOs that are crystalline (Table 2).

In line with $\mathrm{BCO}\left[\mathrm{LLA}_{17}-\mathrm{Si}_{15}\right]{ }^{18}$ enantiomer $\left[\mathrm{DLA}_{17}-\mathrm{Si}_{15}\right]$ revealed a nearly identical pattern of equally spaced reflections $\left(q^{*}, \sqrt{ } 4 q^{*}, \sqrt{ } 9 q^{*}, \ldots\right)$ up to the 11 th reflection $\left(q=\sqrt{ } 121 q^{*}\right)$ (Figure S5A). This pattern signifies the presence of a lamellar structure with very uniform domain sizes. Of the remaining BCOs containing an $o$ DMS with 23 siloxane repeat units, each enantiomeric pair also gave very similar scattering results. We will here discuss the results for the oLLA containing BCOs, but these can be interpreted as being valid for oDLA-oDMS BCOs as well. BCO $\left[\mathrm{LLA}_{9}-\mathrm{Si}_{23}\right]$ 一 the sole block length combination that did not show a crystallization transition in DSC analysisexhibited scattering reflections at $q^{*}, \sqrt{ } 3 q^{*}$ and $\sqrt{ } 7 q^{*}$. This is consistent with a morphology of hexagonally packed cylinders with a domain spacing $d_{\mathrm{CYL}}=6.3 \mathrm{~nm}$. All BCOs with a longer oLLA block showed a significant shift of the primary scattering peak positions to lower $q$ values. Similar to $\left[\mathrm{LLA}_{17}-\mathrm{Si}_{15}\right]$, additional reflections at integer multiples of $q^{*}$ were most prominent, indicative for the presence of a lamellar structure with a domain spacing $d_{\text {cryst }}$. However, the scattering patterns 

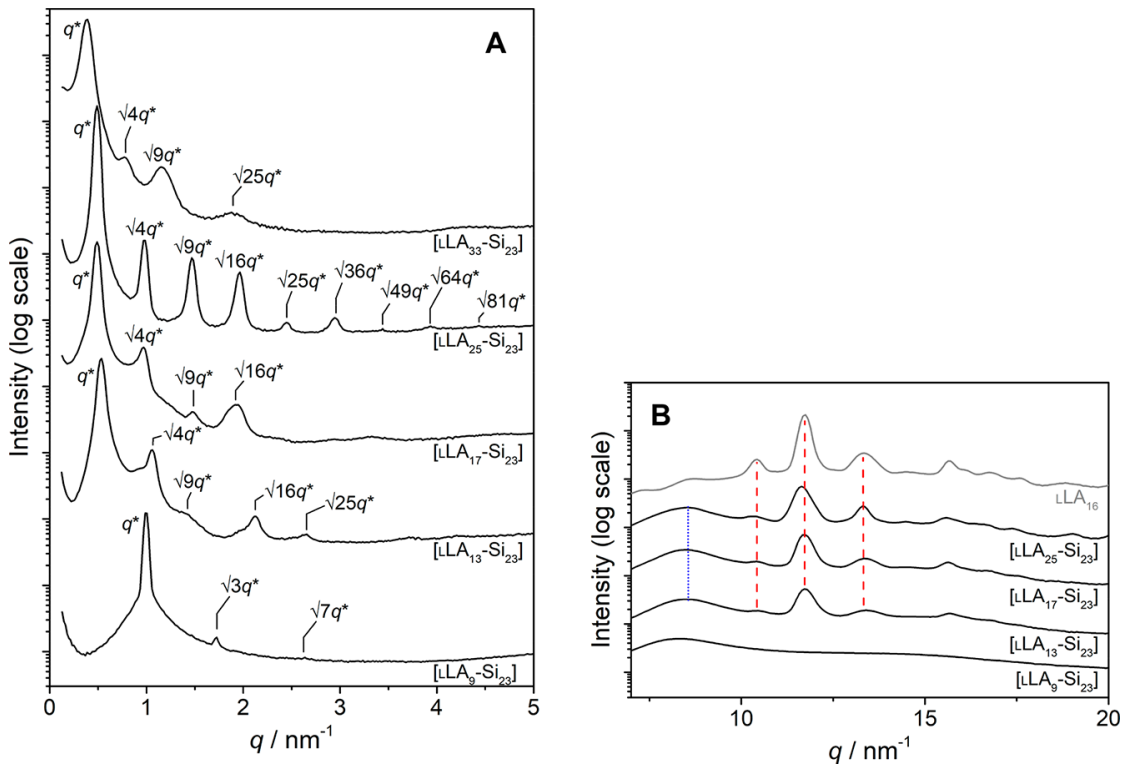

Figure 6. 1-D scattering profiles for $\left[\mathrm{LLA}_{x}-\mathrm{Si}_{23}\right]$ in the low- $q$ range (A) and high- $q$ range (B).
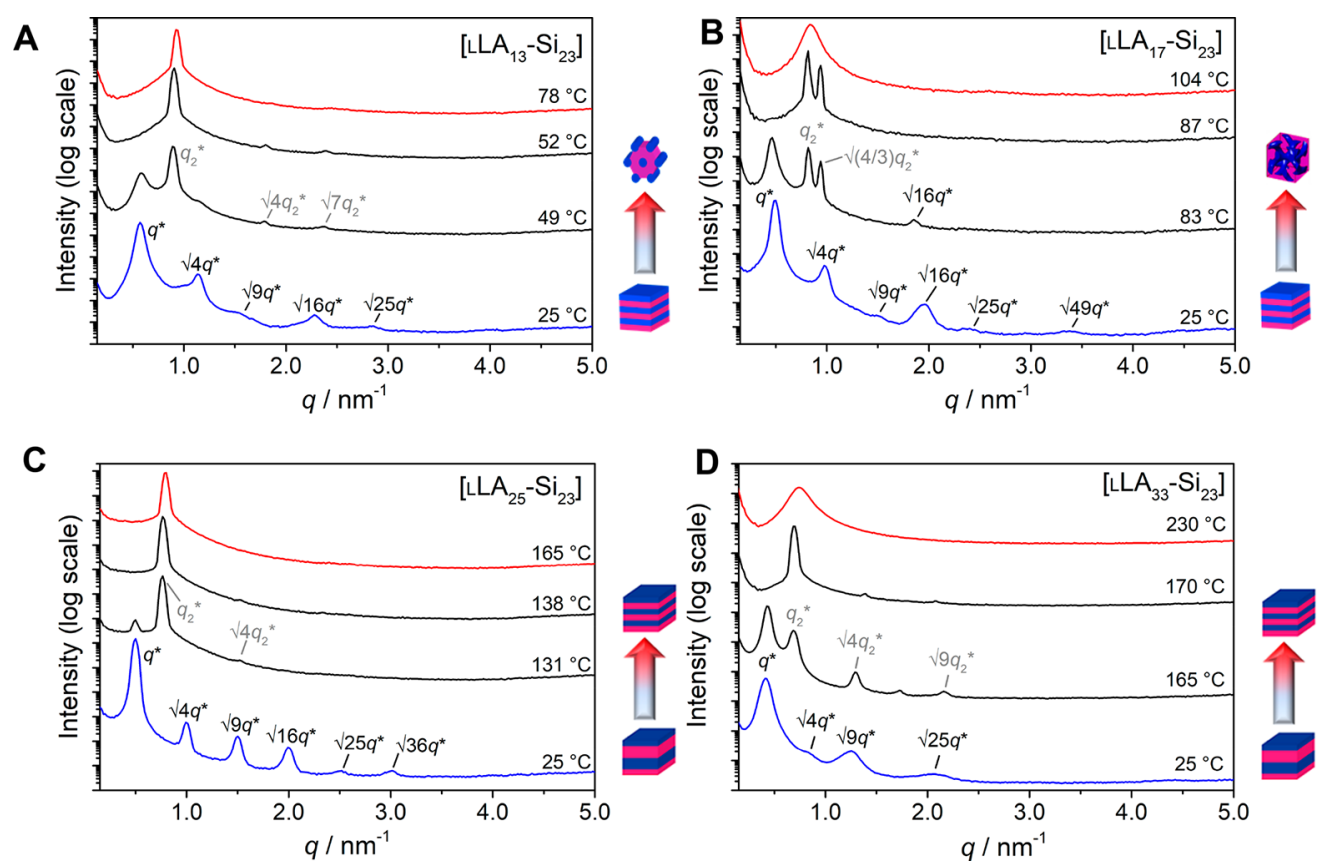

Figure 7. 1-D transmission scattering profiles for $\mathrm{BCOs}\left[\mathrm{LLA}_{13}-\mathrm{Si}_{23}\right]$ (A), $\left[\mathrm{LLA}_{17}-\mathrm{Si}_{23}\right]$ (B), $\left[\mathrm{LLA}_{25}-\mathrm{Si}_{23}\right]$ (C), and $\left[\mathrm{LLA}_{33}-\mathrm{Si}_{23}\right](\mathrm{D})$ at various temperatures.

of $\left[\mathrm{LLA}_{13}-\mathrm{Si}_{23}\right]$ and $\left[\mathrm{LLA}_{17}-\mathrm{Si}_{23}\right]$ looked distorted, mostly expressed as broadened reflections and a shoulders at the low- $q$ side of the $\sqrt{ } 4 q^{*}$ peaks (vide infra).

A multitude of reflections was observed in the $q$ range 5-20 $\mathrm{nm}^{-1}$ for all BCOs except $\left[\mathrm{LLA}_{9}-\mathrm{Si}_{23}\right]$ (Figure 6B). Three reflections around 10.4 ([011]), 11.8 ([110], [200]), and 13.4 $([203]) \mathrm{nm}^{-1}$ dominated in the WAXS region (indicated with the red, dashed lines). For comparison, scattering data of Bn$\mathrm{LLA}_{16}$-TBDMS is added in Figure 6B. The close resemblance of the data suggests that within the lamellar domains formed by the oLLA blocks, an oLLA crystal structure was formed similar to that of the homoblocks. The lack of clear reflections in the scattering pattern of $\left[\mathrm{LLA}_{9}-\mathrm{Si}_{23}\right]$ confirms the noncrystalline state of this BCO. Additionally, a broad reflection with a maximum at $q=8.6 \mathrm{~nm}^{-1}$ (blue, dotted line) was found in the scattering profiles of all BCOs. This reflection is absent in the scattering profiles of the individual oLLA molecules and originates from amorphous chain organization in the oDMS domain.

Furthermore, variable-temperature SAXS measurements were conducted for BCOs $\left[\mathrm{LLA}_{13}-\mathrm{Si}_{23}\right],\left[\mathrm{LLA}_{17}-\mathrm{Si}_{23}\right]$, $\left[\mathrm{LLA}_{25}\right.$ $\left.\mathrm{Si}_{23}\right]$, and $\left[\mathrm{LLA}_{33}-\mathrm{Si}_{23}\right]$ to capture any structural transformations related to the transitions that were observed with the DSC measurements. A selection of 1-D scattering profiles is presented in Figure 7. Generally, little to no changes in the scattering data for any of the four BCOs were observed upon heating from $25^{\circ} \mathrm{C}$ to slightly below the melting temperature. In contrast, within a narrow temperature window around $T_{\mathrm{m}}$ 
significant changes were observed in the scattering profiles. The disappearance of the sharp reflections in the WAXS region above $T_{\mathrm{m}}$ is indicative for the transformation of the crystalline oLLA domain into an amorphous (molten) phase. In addition, there is a loss of the scattering reflections at integer values of $q^{*}$, consistent with a disappearance of the lamellar phase of the BCOs in the crystalline state into a different morphology. The nature of the morphologies formed above $T_{\mathrm{m}}$ is revealed by the appearance of a new primary scattering peak, denoted $q_{2}{ }^{*}$ in Figure 7 , alongside a number of associated higher order reflections. BCO $\left[\mathrm{LLA}_{13}-\mathrm{Si}_{23}\right]$ revealed a new reflection at $q_{2}$ * $=0.89 \mathrm{~nm}^{-1}$ and two additional reflections at $\sqrt{ } 4 q_{2} *$ and $\sqrt{ } 7 q_{2} *$. This confirms a morphology consisting of hexagonally packed oLLA cylinders $\left(d_{\mathrm{CYL}}=7.10\right)$. In BCO [ $\left.\mathrm{LLA}_{17}-\mathrm{Si}_{23}\right]$, scattering reflections observed at $q_{2}{ }^{*}=0.81 \mathrm{~nm}^{-1}$ and $\sqrt{ }(4 / 3)$ $q_{2}{ }^{*}$ indicate a gyroid microphase above $T_{\mathrm{m}}$ with $d_{\text {amorph }}=7.7$ $\mathrm{nm}$. Finally, the two largest $\mathrm{BCOs}\left[\mathrm{LLA}_{25}-\mathrm{Si}_{23}\right]$ and $\left[\mathrm{LLA}_{33}\right.$ $\left.\mathrm{Si}_{23}\right]$ remain in a lamellar morphology after melting of the crystalline block. However, a new primary peak at higher $q$ value indicated a significant decrease in domain spacing to $d_{\text {amorph }}=8.3$ and $9.1 \mathrm{~nm}$ for $\left[\mathrm{LLA}_{25}-\mathrm{Si}_{23}\right]$ and $\left[\mathrm{LLA}_{33}-\mathrm{Si}_{23}\right]$, respectively. These amorphous, microphase-segregated structures for $\mathrm{BCOs}\left[\mathrm{LLA}_{13}-\mathrm{Si}_{23}\right],\left[\mathrm{LLA}_{17}-\mathrm{Si}_{23}\right]$, and $\left[\mathrm{LLA}_{25}-\mathrm{Si}_{23}\right]$ above $T_{\mathrm{m}}$ are fully consistent with the amorphous state morphologies observed in the atactic BCOs. ${ }^{13}$ On the contrary, the oLLA BCOs form a lamellar structure below $T_{\mathrm{m}}$, consisting of alternating, amorphous oDMS blocks and crystalline oLLA blocks. Here, formation of the lamellar phase presumably is governed by the preferred parallel orientation of the oLLA chains in the crystalline state.

Stereocomplex Formation in Discrete-Length (Co)oligomers. The formation and behavior of PLLA and PDLA stereocomplexes is well known and has been elaborately studied, ${ }^{34,36,37}$ but the details of the packing of the chains remain open for debate. ${ }^{38}$ Stereocomplex formation of LA oligomers up to 16 repeating units was systematically studied by Hennink and co-workers, showing crystallization of the blends occurring at DP $\geq 7 .{ }^{39}$ Here, we studied the stereocomplex $(\mathrm{sc})$ formation of $o \mathrm{LLA}_{x}$ and $o \mathrm{DLA}_{x}$ (sc-oLA) homoblocks and the related $\left[\mathrm{LLA}_{x}-\mathrm{Si}_{y}\right]$ and $\left[\mathrm{DLA}_{x}-\mathrm{Si}_{y}\right]$ (sc$\left.\left[\mathrm{LA}_{x}-\mathrm{Si}_{y}\right]\right)$ BCOs by following changes in the thermal and selfassembly behavior. Stereocomplex formation was induced by physical mixing of both enantiomeric forms of $o \mathrm{LA}$ of equal length or, similarly, mixing of $\left[\mathrm{LLA}_{x}-\mathrm{Si}_{y}\right]$ and $\left[\mathrm{DLA}_{x}-\mathrm{Si}_{y}\right]$ of equal MW and composition. Mixing was performed in solution (DCM), and after removal of the solvent, the stereocomplex mixtures were dried under high vacuum. In all cases a 1-to-1 mixing ratio was used.

Interestingly, all stereocomplexes of the $o \mathrm{LA}_{x}$ blocks were solid at room temperature (Table 3, entries $1-6$ ). This is in contrast to the work of Hennink et al., ${ }^{39}$ as we observe that only four LA repeat units are needed to obtain crystalline solids. Most samples crystallized directly after preparation, except sc-LA $\mathrm{LA}_{8}$, which crystallized after storage for 4 months at room temperature. DSC analysis of all samples revealed a significant increase of the melting temperatures and enthalpies, compared to those of the homochiral constituents. Stereocomplexes sc- $\mathrm{LA}_{4}$ and sc-LA $\mathrm{L}_{8}$ melted only once, hence giving a category A thermal profile (Figure S6A). Stereocomplexes of the longer oligomers all showed behavior typical for category $\mathrm{C}$ : direct crystallization when cooled down from the melt with $10 \mathrm{~K} \mathrm{~min}^{-1}$ (Figure S6B).
Table 3. Thermal and Scattering Data for Stereocomplexes of sc-oLA and sc- $\left[\mathrm{LA}_{x}-\mathrm{Si}_{y}\right] \mathrm{BCOs}$

\begin{tabular}{|c|c|c|c|c|c|}
\hline entry & stereocomplex ${ }^{a}$ & $\begin{array}{c}T_{\mathrm{g}}^{b} \\
{\left[{ }^{\circ} \mathrm{C}\right]}\end{array}$ & $\begin{array}{l}T_{\mathrm{m}}{ }^{b} \\
{\left[{ }^{\circ} \mathrm{C}\right]}\end{array}$ & $\begin{array}{c}\Delta H_{\text {fus }}{ }^{b} \\
{\left[\mathrm{~kJ} \mathrm{~mol}{ }^{-1}\right]}\end{array}$ & $\begin{array}{l}d_{\mathrm{LAM}}{ }^{c} \\
{[\mathrm{~nm}]}\end{array}$ \\
\hline 1 & sc- $-\mathrm{LA}_{4}$ & -33.5 & 33.2 & 34.4 & 1.75 \\
\hline 2 & sc-LA 8 & -11.9 & 41.6 & 25.9 & 3.82 \\
\hline 3 & sc- $-\mathrm{LA}_{12}$ & n.d. & 87.7 & 59.7 & 4.52 \\
\hline 4 & sc- $-\mathrm{LA}_{16}$ & n.d. & 143.2 & 302.4 & 5.39 \\
\hline 5 & sc- $-\mathrm{LA}_{32}$ & n.d. & 202.9 & 302.4 & 10.4 \\
\hline 6 & sc- $-\mathrm{LA}_{64}$ & n.d. & 227.3 & 549.2 & 18.6 \\
\hline 7 & $\mathrm{sc}-\left[\mathrm{LA}_{17}-\mathrm{Si}_{15}\right]$ & n.d. & 142.7 & 126.8 & 11.7 \\
\hline 8 & $\mathrm{sc}-\left[\mathrm{LA}_{9}-\mathrm{Si}_{23}\right]$ & n.d. & 74.2 & 41.8 & 9.93 \\
\hline 9 & $\mathrm{sc}-\left[\mathrm{LA}_{13}-\mathrm{Si}_{23}\right]$ & n.d. & 103.8 & 89.3 & 11.7 \\
\hline 10 & $\mathrm{sc}-\left[\mathrm{LA}_{17}-\mathrm{Si}_{23}\right]$ & n.d. & 137.5 & 134.9 & 13.4 \\
\hline
\end{tabular}

${ }^{a}$ Stereocomplex 1:1 ratio of L- and D-LA (co)-oligomers. ${ }^{b}$ Glass transition temperature $\left(T_{\mathrm{g}}\right)$, melt temperature $\left(T_{\mathrm{m}}\right)$, and enthalpy of fusion $\left(\Delta H_{\text {fus }}\right)$. Determined with DSC using a heating rate of $10 \mathrm{~K}$ $\mathrm{min}^{-1}$. Enthalpic values are per mole of oligomer. ${ }^{c}$ Lamellar domain spacing of the crystalline phase determined with SAXS at room temperature, calculated as $d_{\mathrm{LAM}}=2 \pi / q^{*}$; n.d. not determined

All oLA stereocomplexes showed equally spaced, strong reflections in the MAXS region of the scattering profiles, indicating the formation of a lamellar crystal structure (Figure 8A). The lamellar domain spacings were determined and are depicted in Table 3. Most of the domain spacings in the stereocomplexes are almost equal to those found for the homochiral blocks. Surprisingly, the domain spacing of sc-LA 64 was nearly double that of the sc- $\mathrm{LA}_{32}$, indicative for fully stretched oLA chains in the stereocomplex. In contrast to the homoblocks, the enthalpic penalty for chain folding in the stereocomplex sc- $\mathrm{LA}_{64}$ is probably much higher. This outweighs the potential increase in entropy that would result from chain folding and forces the molecules in fully stretched conformation.

Additional scattering measurements in the WAXS region resulted in scattering profiles that looked very similar for all evaluated sc-oLA mixtures (Figure $8 \mathrm{~B}$ ). Typically, three strong reflections were observed at $q=8.4,14.6$, and $16.9 \mathrm{~nm}^{-1}$ indicated with the red, dashed lines. The location of these peaks exactly corresponds to experimentally observed reflections for the well-studied PLA stereocomplex ${ }^{34,36,38}$ and is indicative for the crystallization in a triclinic crystal system. The crystal lattice contains alternating oLLA and oDLA chains that adopt a $3_{1}$ helix, in contrast to the $10_{3}$ helix that was observed for the individual oLLA and oDLA components. Ideally, the $o$ LA chains pack in a parallel fashion; ${ }^{34}$ however, this remains open for debate.

Stereocomplex formation was also observed in the $1: 1$ mixtures of $\left[\mathrm{LLA}_{x}-\mathrm{Si}_{y}\right]$ and $\left[\mathrm{DLA}_{x}-\mathrm{Si}_{y}\right]$ (Table 3, entries 7-10). The evaluated $\mathrm{BCO}$ stereocomplexes were all solids at room temperature and showed melting and crystallization transitions at approximately $60{ }^{\circ} \mathrm{C}$ higher temperatures than the homochiral BCOs (Figure S7). This also rationalizes the possibility to crystallize sc- $\left[\mathrm{LA}_{9}-\mathrm{Si}_{23}\right]$, which did not crystallize as the homochiral analogue. Furthermore, very sharp crystallization transitions are observed in the DSC measurements, which is most pronounced for sc- $\left[\mathrm{LA}_{17}-\mathrm{Si}_{23}\right]$ (Figure 9). No order-disorder transitions were found. Presumably the (expected) $T_{\mathrm{ODT}}$ is lower than $T_{\mathrm{m}}$, and thus, the melting transition directly results in a disordered state. Overall, we can confirm that also in the BCOs the crystallization into the stereocomplex crystal structure is more stable than that of the 

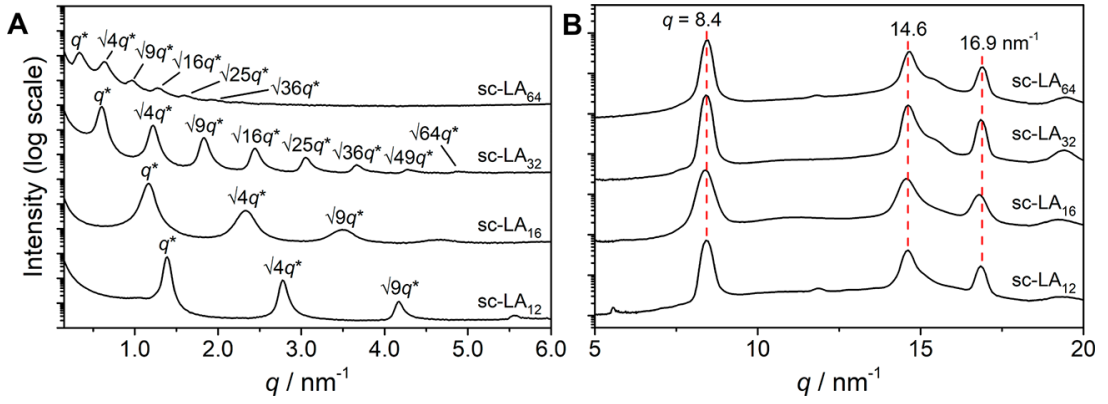

Figure 8. 1-D transmission scattering profiles for sc-oLA of various lengths in the low- $q$ range (A) and high- $q$ range (B).

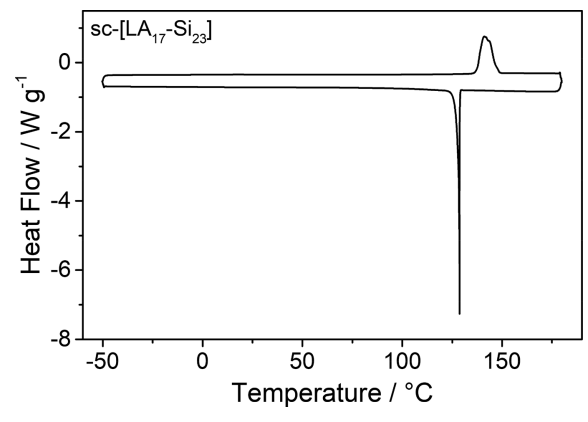

Figure 9. DSC trace (second heating and cooling run) for sc- $\left[\mathrm{LA}_{17^{-}}\right.$ $\left.\mathrm{Si}_{23}\right]$ showing the facile crystallization upon cooling. Endothermic heat flows have a positive value. Temperature ramp of $10 \mathrm{~K} \mathrm{~min}^{-1}$ was used.

homochiral crystal structure as a result of a fast crystallization rate.

The self-assembled, crystalline structures were evaluated with X-ray scattering. The presence of a lamellar microstructure was confirmed by the appearance of equally spaced reflections in the MAXS region (Figure 10A). Furthermore, the reflections at higher $q$ values perfectly overlap with the aforementioned reflections indicative for a triclinic unit cell of stereocomplex PLA (Figure 10B). This confirmed the presence of stereocomplex interactions within the oLA domain. Remarkably, significant broadening of the reflections that originate from the lamellar packing is observed, indicative for an increase in the local level of defects in the lamellar packing. Currently, it is unclear why the stereocomplexation in the BCOs causes these higher variations in lamellar thickness and diminished long-range order. We propose that there is a relation with the sharp crystallization transition and a larger thermodynamic driving force for crystallization, which impedes defect minimization during the crystallization process. Most likely, this results from an unbalance of the diffusion kinetics and relatively fast crystallization of the individual oLA (or $\mathrm{BCO})$ chains. In addition, it is known that neighboring molecules in the PLA stereocomplex are prone to exhibit shift disorder, which might further contribute to broadening of the scattering reflections. ${ }^{34}$

\section{CONCLUSIONS}

We successfully synthesized isotactic L- and D-lactic acid oligomers with a discrete length up to 64 repeating units via an iterative approach. Ligation of the oLLA and oDLA blocks to monodisperse $o$ DMS blocks afforded oLLA-oDMS and oDLA$o$ DMS diblock co-oligomers, respectively. The synthetic accessibility of both enantiomeric LA oligomers and the BCOs provide the opportunity to not only study the isotactic $o \mathrm{LA}$ and BCO thermal and self-assembly behavior but also examine their stereocomplexes. Discrete-length, isotactic oLA has a strong tendency to form a well-organized crystalline phase in which the oLA chains form a $10_{3}$ helix with a monomeric rise of $0.3 \mathrm{~nm}$, whereas the stereocomplex of $o \mathrm{LLA}$ and $o$ DLA adopts a $3_{1}$ helix. Hence, the tighter packing of the stereocomplex causes stretching of the longest oligomer with 64 repeating units that is folded in the isotactic oLA crystal. The propensity observed to crystallize into a lamellar macrolattice was exploited in the self-assembly of the crystalline BCOs. The low molecular weight character resulted in an extended-chain conformation of the oLA chains in either a $10_{3}$ or a $3_{1}$ helix for the homochiral or stereocomplex BCOs, respectively. The tendency of the $o$ LA chains to crystallize into their most stable crystalline lattice, similar to those of the oLLA and $o$ DLA building blocks, results in the formation of a lamellar morphology independent of the $\mathrm{BCO}$ volume fraction. Above $T_{\mathrm{m}}$ and below $T_{\mathrm{ODT}}$ the homochiral BCOs formed an amorphous, phase-separated structure similar to the atactic BCO analogues of equal length and composition. ${ }^{13}$ However, the $T_{\mathrm{ODT}}$ values of the BCOs that contain an isotactic lactic acid block are higher, suggesting an increase in $\chi_{\text {eff }}$ between
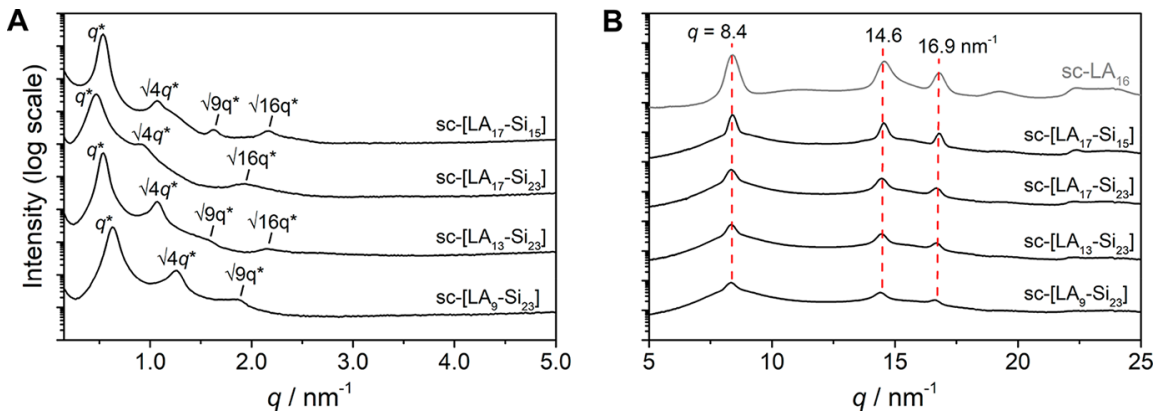

Figure 10. 1-D transmission scattering profiles for various BCO stereocomplexes in the low- $q$ range (A) and high- $q$ range (B). 
$o$ DMS and $o$ LLA or oDLA compared to the combination of $o$ DMS and atactic $o$ LA. The higher $\chi_{\text {eff }}$ could in principle increase the mesoscale organization, but the formation of solely lamellar structures reveals that the large driving force for crystallization impedes this organization. The $T_{\mathrm{ODT}}$ completely disappears upon formation of the stereocomplex BCOs due to an increase of the melting temperature, indicative for a more stable crystal structure. However, more crystal defects and a loss of long-range ordering in the microstructure are observed for the stereocomplex. We propose that this is a result of a fast crystallization rate and a larger thermodynamic driving force for crystallization.

Finally, we conclude for the semicrystalline BCOs that the balance between crystallization rate, preorganization in the amorphous state, and dimensions of the anticipated crystalline structure are key for obtaining the organization with the least defects. Breakout crystallization is very likely to occur as most of the systems either stay disordered or reside in a very weakly phase-segregated state at temperatures above $T_{\mathrm{m}}$ of the crystalline blocks. $^{21}$ However, crystallization-induced transformation of these amorphous phase-segregated state into alternating crystalline-amorphous lamellar domains incidentally requires the (local) migration of a large number of molecules. Arguably, displacement of low-MW molecules and preorganization of the $\mathrm{BCO}$ in a phase that already resembles that of the final crystalline state (e.g., in $\left[\mathrm{LLA}_{25}-\mathrm{Si}_{23}\right]$ ) is very beneficial. On the contrary, materials that initially formed nonlamellar morphologies show more distorted lamellar structures after crystallization (e.g., $\left[\mathrm{LLA}_{13}-\mathrm{Si}_{23}\right]$ ). Hence, finding a balance between chain length, block volume, and crystallization strength is of major importance for the formation of the final structure. This systematic study of low-MW semicrystalline BCOs gives insight into the molecular and mesoscale organization of oLA chains in these BCOs. This opens the discussion on the fading boundaries between liquid crystal and BCP self-assembly in which often only molecular or mesoscale organization are addressed. The relationship between both length scales is key to develop new properties for polymers, and therefore, we propose these and related materials are crucial to enable the design of new polymeric materials.

\section{ASSOCIATED CONTENT}

\section{S Supporting Information}

The Supporting Information is available free of charge on the ACS Publications website at DOI: 10.1021/acs.macromol.8b02529.

Materials and methods, synthetic procedures, thermal analysis of oLLA and oDLA homoblocks, thermal analysis of $O D L A-o D M S$ and $O L L A-o D M S$, SAXS measurements of $o$ DLA-oDMS, thermal analysis and SAXS measurements of homoblock and BCO stereocomplexes, MALDI-TOF analysis of homoblocks and BCOs, and references (PDF)

\section{AUTHOR INFORMATION}

\section{Corresponding Author}

*E-mail: e.w.meijer@tue.nl.

ORCID $\odot$

Anja R. A. Palmans: 0000-0002-7201-1548

E. W. Meijer: 0000-0003-4126-7492

\section{Author Contributions}

${ }^{\dagger}$ B.A.G.L. and B.v.G.: These authors contributed equally.

\section{Author Contributions}

The manuscript was written through contributions of all authors. All authors have given approval to the final version of the manuscript.

\section{Notes}

The authors declare no competing financial interest.

J.H.: Deceased January 9, 2017

\section{ACKNOWLEDGMENTS}

This work is financed by the Royal Netherlands Academy of Arts and Sciences and the Dutch Ministry of Education, Culture and Science (Gravity program 024.001.035).

\section{REFERENCES}

(1) Leibler, L. Theory of Microphase Separation in Block Copolymers. Macromolecules 1980, 13 (10), 1602-1617.

(2) Bates, C. M.; Bates, F. S. 50th Anniversary Perspective: Block Polymers-Pure Potential. Macromolecules 2017, 50 (1), 3-22.

(3) Sinturel, C.; Bates, F. S.; Hillmyer, M. A. High $\chi$-Low N Block Polymers: How Far Can We Go? ACS Macro Lett. 2015, 4 (9), 10441050.

(4) Kennemur, J. G.; Yao, L.; Bates, F. S.; Hillmyer, M. A. Sub-5 Nm Domains in Ordered Poly(cyclohexylethylene)- Block -Poly(methyl Methacrylate) Block Polymers for Lithography. Macromolecules 2014, 47 (4), 1411-1418.

(5) Otsuka, I.; Zhang, Y.; Isono, T.; Rochas, C.; Kakuchi, T.; Satoh, T.; Borsali, R. Sub-10 Nm Scale Nanostructures in Self-Organized Linear Di- and Triblock Copolymers and Miktoarm Star Copolymers Consisting of Maltoheptaose and Polystyrene. Macromolecules 2015, 48 (5), 1509-1517.

(6) Bates, C. M.; Maher, M. J.; Janes, D. W.; Ellison, C. J.; Willson, C. G. Block Copolymer Lithography. Macromolecules 2014, 47 (1), $2-12$.

(7) Jeong, G.; Yu, D. M.; Mapas, J. K. D.; Sun, Z.; Rzayev, J.; Russell, T. P. Realizing 5.4 Nm Full Pitch Lamellar Microdomains by a SolidState Transformation. Macromolecules 2017, 50 (18), 7148-7154.

(8) Kwak, J.; Mishra, A. K.; Lee, J.; Lee, K. S.; Choi, C.; Maiti, S.; Kim, M.; Kim, J. K. Fabrication of Sub-3 Nm Feature Size Based on Block Copolymer Self-Assembly for Next-Generation Nanolithography. Macromolecules 2017, 50 (17), 6813-6818.

(9) Carter, M. C. D.; Jennings, J.; Speetjens, F. W.; Lynn, D. M.; Mahanthappa, M. K. A Reactive Platform Approach for the Rapid Synthesis and Discovery of High $\chi$ /Low N Block Polymers. Macromolecules 2016, 49 (17), 6268-6276.

(10) Chen, Q. P.; Barreda, L.; Oquendo, L. E.; Hillmyer, M. A.; Lodge, T. P.; Siepmann, J. I. Computational Design of High- $\chi$ Block Oligomers for Accessing 1-Nanometer Domains. ACS Nano 2018, 12 (5), 4351-4361.

(11) Rokhlenko, Y.; Kawamoto, K.; Johnson, J. A.; Osuji, C. O. Sub$10 \mathrm{Nm}$ Self-Assembly of Mesogen-Containing Grafted Macromonomers and Their Bottlebrush Polymers. Macromolecules 2018, 51 (10), 3680-3690.

(12) Gentekos, D. T.; Fors, B. P. Molecular Weight Distribution Shape as a Versatile Approach to Tailoring Block Copolymer Phase Behavior. ACS Macro Lett. 2018, 7 (6), 677-682.

(13) Van Genabeek, B.; de Waal, B. F. M.; Gosens, M. M. J.; Pitet, L. M.; Palmans, A. R. A.; Meijer, E. W. Synthesis and Self-Assembly of Discrete Dimethylsiloxane-Lactic Acid Diblock Co-Oligomers: The Dononacontamer and Its Shorter Homologues. J. Am. Chem. Soc. 2016, 138 (12), 4210-4218.

(14) Van Genabeek, B.; De Waal, B. F. M.; Ligt, B.; Palmans, A. R. A.; Meijer, E. W. Dispersity under Scrutiny: Phase Behavior Differences between Disperse and Discrete Low Molecular Weight Block Co-Oligomers. ACS Macro Lett. 2017, 6 (7), 674-678. 
(15) Oschmann, B.; Lawrence, J.; Schulze, M. W.; Ren, J. M.; Anastasaki, A.; Luo, Y.; Nothling, M. D.; Pester, C. W.; Delaney, K. T.; Connal, L. A.; et al. Effects of Tailored Dispersity on the SelfAssembly of Dimethylsiloxane-Methyl Methacrylate Block CoOligomers. ACS Macro Lett. 2017, 6 (7), 668-673.

(16) Jiang, Y.; Golder, M. R.; Nguyen, H. V. T.; Wang, Y.; Zhong, M.; Barnes, J. C.; Ehrlich, D. J. C.; Johnson, J. A. Iterative Exponential Growth Synthesis and Assembly of Uniform Diblock Copolymers. J. Am. Chem. Soc. 2016, 138 (30), 9369-9372.

(17) Zha, R. H.; De Waal, B. F. M.; Lutz, M.; Teunissen, A. J. P.; Meijer, E. W. End Groups of Functionalized Siloxane Oligomers Direct Block-Copolymeric or Liquid-Crystalline Self-Assembly Behavior. J. Am. Chem. Soc. 2016, 138 (17), 5693-5698.

(18) van Genabeek, B.; Lamers, B. A. G.; de Waal, B. F. M.; van Son, M. H. C.; Palmans, A. R. A.; Meijer, E. W. Amplifying (Im)perfection: The Impact of Crystallinity in Discrete and Disperse Block CoOligomers. J. Am. Chem. Soc. 2017, 139 (42), 14869-14872.

(19) Van Genabeek, B.; de Waal, B. F. M.; Palmans, A. R. A.; Meijer, E. W. Discrete Oligodimethylsiloxane-Oligomethylene $\mathrm{Di}$ - and Triblock Co-Oligomers: Synthesis and Self-Assembly and Molecular Organization. Polym. Chem. 2018, 9 (20), 2746-2758.

(20) He, W. N.; Xu, J. T. Crystallization Assisted Self-Assembly of Semicrystalline Block Copolymers. Prog. Polym. Sci. 2012, 37 (10), $1350-1400$

(21) Nandan, B.; Hsu, J. Y.; Chen, H. L. Crystallization Behavior of Crystalline-Amorphous Diblock Copolymers Consisting of a Rubbery Amorphous Block. J. Macromol. Sci., Polym. Rev. 2006, 46 (2), 143172.

(22) Takeshita, H.; Shiomi, T.; Takenaka, K.; Arai, F. Crystallization and Higher-Order Structure of Multicomponent Polymeric Systems. Polymer 2013, 54 (18), 4776-4789.

(23) Loo, Y. L.; Register, R. A.; Ryan, A. J. Modes of Crystallization in Block Copolymer Microdomains: Breakout, Templated, and Confined. Macromolecules 2002, 35 (6), 2365-2374.

(24) Nojima, S.; Inokawa, D.; Kawamura, T.; Nitta, K. Dynamic Mechanical Study of Block Copolymer Crystallization Confined within Spherical Nanodomains. Polym. J. 2008, 40 (10), 986-991.

(25) Quiram, D. J.; Register, R. A.; Marchand, G. R. Crystallization of Asymmetric Diblock Copolymers from Microphase-Separated Melts. Macromolecules 1997, 30 (16), 4551-4558.

(26) Rangarajan, P.; Register, R. A.; Fetters, L. J. Morphology of Semicrystalline Block Copolymers of Ehtylene-(Ethylene-Alt-Propylene). Macromolecules 1993, 26, 4640-4645.

(27) DiMarzio, E. A.; Guttman, C. M.; Hoffman, J. D. Calculation of Lamellar Thickness in a Diblock Copolymer, One of Whose Components Is Crystalline. Macromolecules 1980, 13 (5), 1194-1198.

(28) Huang, S.; Jiang, S. Structures and Morphologies of Biocompatible and Biodegradable Block Copolymers. RSC Adv. 2014, 4 (47), 24566.

(29) Panthani, T. R.; Bates, F. S. Crystallization and Mechanical Properties of Poly(1-Lactide)-Based Rubbery/Semicrystalline Multiblock Copolymers. Macromolecules 2015, 48 (13), 4529-4540.

(30) Hawker, C. J.; Wooley, K. L. The Convergence of Synthetic Organic and Polymer Chemistry. Science (Washington, DC, U. S.) 2005, 309 (5738), 1200-1205.

(31) Takizawa, K.; Nulwala, H.; Hu, J.; Yoshinaga, K.; Hawker, C. J. Molecularly Defined (L)-Lactic Acid Oligomers and Polymers: Synthesis and Characterization. J. Polym. Sci., Part A: Polym. Chem. 2008, 46 (18), 5977-5990.

(32) De Santis, P.; Kovacs, J. Molecular Conformation of Poly (Slactic Acid). Biopolymers 1968, 6 (3), 299-306.

(33) Tsuji, H. Polylactides. In Polyesters 3; Doi, Y., Steinbuchel, A., Eds.; Wiley-VCH: Weinheim, 2002; Vol. 4 (Biopolymers), pp 129177.

(34) Okihara, T.; Tsuji, M.; Kawaguchi, A.; Katayama, K.-I.; Tsuji, H.; Hyon, S.-H.; Ikada, Y. Crystal Structure of Stereocomplex of poly(L-Lactide) and poly(D-Lactide). J. Macromol. Sci., Part B: Phys. 1991, 30 (1), 119-140.
(35) Rubinstein, M.; Colby, R. H. Polymer Physics; Oxford University Press Inc.: New York, 2003.

(36) Tsuji, H. Poly(lactide) Stereocomplexes: Formation, Structure, Properties, Degradation, and Applications. Macromol. Biosci. 2005, 5 (7), 569-597.

(37) Tsuji, H.; Arakawa, Y. Synthesis, Properties, and Crystallization of the Alternating Stereocopolymer poly(L-Lactic Acid-Alt-D-Lactic Acid) [Syndiotactic Poly(lactic Acid)] and Its Plend with Isotactic Poly(lactic Acid). Polym. Chem. 2018, 9, 2446-2457.

(38) Tashiro, K.; Kouno, N.; Wang, H.; Tsuji, H. Crystal Structure of Poly(lactic Acid) Stereocomplex: Random Packing Model of PDLA and PLLA Chains As Studied by X-Ray Diffraction Analysis. Macromolecules 2017, 50 (20), 8048-8065.

(39) de Jong, S. J.; van Dijk-Wolthuis, W. N. E.; Kettenes-van den Bosch, J. J.; Schuyl, P. J. W.; Hennink, W. E. Monodisperse Enantiomeric Lactic Acid Oligomers: Preparation, Characterization, and Stereocomplex Formation. Macromolecules 1998, 31 (19), 63976402 . 